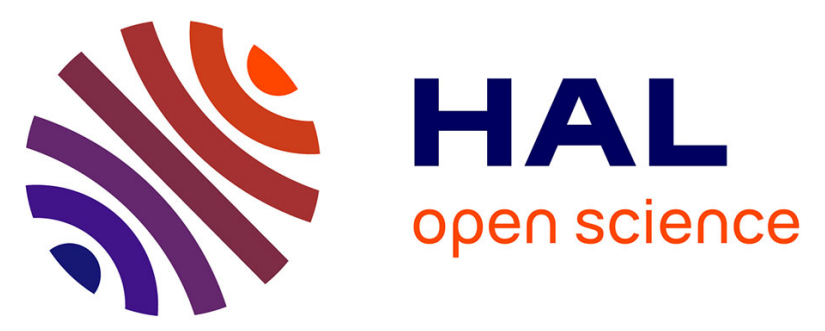

\title{
Assessment of formulation robustness for nano-crystalline suspensions using failure mode analysis or derisking approach
}

Mostafa Nakach, Jean-Rene Authelin, Cecile Voignier, Tharwat Tadros, Laurence Galet, Alain Chamayou

\section{To cite this version:}

Mostafa Nakach, Jean-Rene Authelin, Cecile Voignier, Tharwat Tadros, Laurence Galet, et al.. Assessment of formulation robustness for nano-crystalline suspensions using failure mode analysis or derisking approach. International Journal of Pharmaceutics, 2016, 506 (1-2), p. 320-331. 10.1016/j.ijpharm.2016.04.043 . hal-01593327

\section{HAL Id: hal-01593327 \\ https://hal.science/hal-01593327}

Submitted on 2 Jul 2018

HAL is a multi-disciplinary open access archive for the deposit and dissemination of scientific research documents, whether they are published or not. The documents may come from teaching and research institutions in France or abroad, or from public or private research centers.
L'archive ouverte pluridisciplinaire $\mathbf{H A L}$, est destinée au dépôt et à la diffusion de documents scientifiques de niveau recherche, publiés ou non, émanant des établissements d'enseignement et de recherche français ou étrangers, des laboratoires publics ou privés. 


\title{
Assessment of formulation robustness for nano-crystalline suspensions using failure mode analysis or derisking approach
}

\author{
Mostafa Nakach ${ }^{\mathrm{a}, *}$, Jean-René Authelin ${ }^{\mathrm{a}}$, Cecile Voignier ${ }^{\mathrm{c}}$, Tharwat Tadros ${ }^{\mathrm{b}}$, \\ Laurence Galet ${ }^{\mathrm{c}}$, Alain Chamayou ${ }^{\mathrm{C}}$
}

a Sanofi RED, 13, quai Jules Guesde, 94403 Vitry sur Seine, France

b 89 Nash Grove Lane, Wokingham, Berkshire RG40 4HE, UK

${ }^{\mathrm{c}}$ Ecole des Mines d'Albi, Campus Jarlard, Route de Teillet 83013 Albi France, France

The small particle size of nano-crystalline suspensions can be responsible for their physical instability during drug product preparation (downstream processing), storage and administration. For that purpose, the commercial formulation needs to be sufficiently robust to various triggering conditions, such as ionic strength, shear rate, wetting/dispersing agent desorption by dilution, temperature and $\mathrm{pH}$ variation. In our previous work we described a systematic approach to select the suitable wetting/dispersant agent for the stabilization of nano-crystalline suspension. In this paper, we described the assessment of the formulation robustness (stabilized using a mixture of sodium dodecyl sulfate (SDS) and polyvinylpyrrolidone (PVP) and) by measuring the rate of perikinetic (diffusion-controlled) and orthokinetic (shearinduced) aggregation as a function of ionic strength, temperature, $\mathrm{pH}$ and dilution. The results showed that, using the SDS/PVP system, the critical coagulation concentration is about five times higher than that observed in the literature for suspension colloidaly stable at high concentration. The nano-suspension was also found to be very stable at ambient temperature and at different $\mathrm{pH}$ conditions. Desorption test confirmed the high affinity between API and wetting/dispersing agent. However, the suspension undergoes aggregation at high temperature due to the desorption of the wetting/dispersing agent and disaggregation of SDS micelles. Furthermore, aggregation occurs at very high shear rate (orhokinetic aggregation) by overcoming the energy barrier responsible for colloidal stability of the system.

\section{Introduction}

Nano-crystalline suspensions are used in pharmaceutical industry to enhance biopharmaceutical performances of highly water insoluble active pharmaceutical ingredient (API). Their colloidal particle size range offers the advantage of large surface area per unit volume that provides the required properties of the final product (Shegokar and Müller, 2010). For the preparation of nano-crystalline suspensions, the particle size reduction is the most commonly used method due to the possibility of controlling particle size by suitable selection of wetting/dispersing agent, as well as by control of milling process parameters (Peltonen and Hirvonen, 2010). The ability of nano-crystalline suspension to

\footnotetext{
* Corresponding author.

E-mail addresses: mostafa.nakach@sanofi.com (M. Nakach) Jean-Rene.Authelin@sanofi.com (J.-R. Authelin), cecile.voignier@mines-albi.fr (C. Voignier), tharwat@tadros.fsnet.co.uk (T. Tadros), laurence.Galet@mines-albi.fr (L. Galet), alain.chamayou@mines-albi.fr (A. Chamayou).
}

remain in its original state during drug product preparation and administration (processing or in use handling) is critical for since any change could negatively impact its performances. In fact, all suspensions having particle size less than $1 \mu \mathrm{m}$ are inherently thermodynamically unstable due to the natural tendency decrease the large specific surface area and excess surface energy (Patel, 2010). For this purpose, wetting/dispersing agents are used to stabilize the suspension against flocculation (Holthoff et al., 1996; Lauten et al., 2001) and crystal growth (Ostwald ripening (Ostwald, 1901)).

In a previous work (Nakach et al., 2014), we described a systematic approach to select a suitable wetting/dispersing agent for the preparation of nano-crystalline suspensions. The objective of this paper is to describe the derisking approach implemented for the robustness assessment of the selected formulation with regard to the identified risks that are listed below:

(i) Particles agglomeration during milling: During high-energy milling, the size of particles decreases to some critical values. 
Further energy supply to these particles of limiting size causes further deformation of particles, energy accumulation in the volume or at the surface of particles, and subsequently leads to aggregation. To evaluate such risk, a long milling duration $(13 \mathrm{~h})$ at high shear rate was carried in order to evaluate if the suspension undergoes negative milling phenomenon which is in close relation with aggregation and agglomeration (Anderson and Lekkerkerker, 2002).

(ii) Aggregation during storage or administration due to the lack of electrostatic stabilization: Aggregation occurs if the energy barrier is small or negligible. According to Sato and Ruch (1980), an energy barrier of $15 \mathrm{k}_{\mathrm{B}} \mathrm{T}$ is sufficient to prevent aggregation since thermal energy is $1 k_{B} T$, where, $k_{B}$ is Boltzmann constant and $\mathrm{T}$ is the absolute temperature. The height of the energy barrier depends on the electrolyte concentration which is directly related to the thickness of the double layer. Basically, when a salt is added to the suspension, the electrical double layer repulsion is screened, and van der Waals attraction becomes dominant and induces fast aggregation of particles (Yu and von Gottberg, 2002). At critical electrolyte concentration (CCC) the energy maximum disappears leading to fast aggregation of particles. In our work, the CCC was determined by quantification of aggregation rate as a function of electrolyte addition.

(iii) Shear-induced aggregation (orthokinetic aggregation): Aggregation processes are always carried out under conditions where suspension is subjected to some shear by stirring or by flow leading to increase of collision frequency (Potanin, 1991). In our study, Orthokinetic aggregation was evaluated under a fixed shear rate.

(iv) Aggregation by desorption of wetting/dispersing agent from particles surface: Robustness to dilution is important for nano-crystalline suspension to ensure that the particles formed have similar properties at different dilutions to achieve uniform drug release profile and to ensure that the drug will not get aggregation at higher dilutions in vivo which may significantly impact biopharmaceutical attributes of the product. We had previously, demonstrated that the adsorption of polymeric surfactants (PVP K30) led to high affinity isotherm implying that such process is irreversible (Nakach et al., 2014). To check the irreversibility of adsorbed surfactant, desorption of surfactant from particles surface was investigated by diluting the suspension in water.

(v) Crystal growth due to Ostwald repining and/or flocculation by depletion at high temperature: During milling or autoclaving (in case of suspension use in parenteral administration), the suspension could be submitted to high temperature. In this case, large particles grow with time at the expense of the smaller ones (Ostwald, 1901) due to the well-known Kelvin effect (Hiemenz and Rajagopalan, 1997). Furthermore, high temperature can lead to desorption of polymer molecules which become more soluble (Tadros, 2012) or precipitate when the temperature is higher than polymer cloud point (Corti et al., 1984). Consequently, the non-adsorbing polymer molecules can induce flocculation by depletion interaction between colloidal particles (Jenkins and Snowden, 1996). In this paper, we evaluated the sensitivity of suspension to Ostwald repining and/or flocculation by depletion at high temperature.

(vi) Flocculation due to $\mathrm{pH}$ variation: According to the route of administration, an API experiences a wide range of physiological pH. Accordingly, nano-suspension needs to be robustly designed with regards to $\mathrm{pH}$ variations which may significantly affect the effectiveness of electrostatic stabilization (Kiratzis et al., 1999). Indeed, pH is an important parameter to be taken into account because the particle surface is strongly modified by acid-base equilibriums, and the particle charge may vary from negative to zero and to positive values. In fact, by varying the $\mathrm{pH}$, the isoelectric point (IEP) can be reached. The IEP is the $\mathrm{pH}$ value at which the zeta potential value is zero, implying no electric charge on the surface of a particle. For that purpose, the sensitivity of our formulation to $\mathrm{pH}$ variations was investigated.

\section{Experimental}

\subsection{Material and methods}

\subsubsection{Materials}

A hydrophobic highly insoluble API powder was provided by Sanofi R\&D (Paris). It was micronized by jet milling before use. The physico-chemical properties of the API are given in Table 1.

Polyvinylpyrrolidone PVP (K30) (Molar mass: 30,000 g) was purchased from BASF (France), sodium dodecyl sulfate (SDS) was purchased from Univar (France), Vitamin E TPGS ${ }^{\circledR}$ (d-alpha tocopheryl polyethylene glycol 1000 succinate) was purchased from Eastman Chemical Company (Netherlands), Solutol ${ }^{\circledR}$ HS15 was purchased from BASF (France) and Sodium chloride was purchased from Sigma Aldrich (France).

\subsubsection{Methods}

\subsubsection{Suspension preparation}

2.1.2.1.1. Preparation of milled suspension for evaluation of perikinetic aggregation, orthokinetic aggregation, sensitivity to temperature and $\mathrm{pH}$ variation. The milled suspensions were prepared using API at concentration of $20 \%(\mathrm{w} / \mathrm{w})$ and SDS/PVP as wetting/dispersing agent at concentration of $1.2 \%(\mathrm{w} / \mathrm{w})$. An aliquot of $50 \mathrm{ml}$ suspension and $50 \mathrm{ml}$ of Cross-linked Polystyrene beads $(500 \mu \mathrm{m}$ diameter supplied by Alkermes (USA)) were introduced in Nano-mill $01^{\mathbb{R}}$ (annular mill purchased from Alkermes, having a stator of $80 \mathrm{~mm}$ diameter and rotor of $73 \mathrm{~mm}$ ). The mill was operated during $150 \mathrm{~min}$ at $10.8 \mathrm{~m} / \mathrm{s}$. The mill temperature was maintained at $10^{\circ} \mathrm{C}$.

2.1.2.1.2. Assessment of suspension behavior during long milling duration trial. In our previous work, the screening of wetting/ dispersing agent was carried out in two parts (Nakach et al., 2014):

(i) Part 1 focused on qualitative screening to select the lead candidate. At the end of this part two formulations appeared clearly superior to the others: SDS/PVP and Vitamin E TPGS ${ }^{\mathbb{R}}$.

(ii) Part 2 focused on quantitative screening aimed to optimize the selected lead. For this part, the SDS/PVP made from ionic surfactant (SDS) and polymer (PVP) considered as more relevant was selected for the optimization.

In the present study, we decided to compare the suspension made of SDS/PVP to that made of vitamin $\mathrm{ETPGS}^{\circledR}$ (as reference) in

Table 1

Physico-chemical properties of the API used for this study.

\begin{tabular}{lc}
\hline Average particle diameter & $5 \mu \mathrm{m}$ \\
\hline Molecular weight $(\mathrm{g} / \mathrm{mol})$ & 497.4 \\
Water solubility $(\mu \mathrm{g} / \mathrm{ml})$ & 0.2 \\
Log $P^{\mathrm{a}}$ & 6.9 \\
Density $(\mathrm{g} / \mathrm{ml})$ & 1.42 \\
Melting point $\left({ }^{\circ} \mathrm{C}\right)$ & 156.7 \\
\hline
\end{tabular}

${ }^{\mathrm{a}} \mathrm{P}$ is the partition coefficient between octanol and water. 
terms of their resistance when they are submitted to high shear rate during a long milling duration $(13 \mathrm{~h})$

The milled suspensions were prepared as follows:

- Suspension A made of API at concentration of $20 \%(w / w)$ and SDS/PVP as wetting/dispersing agent at concentration of $1.2 \%$.

- Suspension B made of API at concentration of $20 \%(w / w)$ and Vitamin E TPGS ${ }^{\circledR}$ as wetting/dispersing agent at concentration of $3 \%$.

$50 \mathrm{ml}$ aliquot of each suspension and $50 \mathrm{ml}$ of Cross-linked Polystyrene beads $(500 \mu \mathrm{m})$ were introduced in Nano-mill $01^{\circledR}$ The mill was operated during $13 \mathrm{~h}$ at $11.6 \mathrm{~m} / \mathrm{s}$. The mill temperature was maintained at $10^{\circ} \mathrm{C}$.

The mean shear rate generated during milling can be calculated according the Eq. (1) (Spicer et al., 1996).

$\dot{\gamma}=\sqrt{\frac{\boldsymbol{P}_{v}}{\eta}}$

where, $\eta$ is the suspension viscosity and $P v$ is the power density determined according the equation

$\boldsymbol{P}_{\boldsymbol{v}}=\frac{\boldsymbol{P}}{\boldsymbol{V}}$

$P$ is the net power draw (58 W) measured during milling using wattmeter and $V$ is the suspension volume $(50 \mathrm{ml})$

The main shear rate was found about $22000 \mathrm{~s}^{-1}$.

The overall strain generated during milling can be calculated according the Eq. (3)

$\gamma=\dot{\gamma} * \mathrm{t}=1.010^{9}$

where $t$ is the milling duration

2.1.2.1.3. Preparation milled suspension for desorption evaluation. For desorption assessment, we compared the suspension made of SDS/PVP to that made of solutol ${ }^{\circledR}$ (as reference) which was gated out from the screening done in our previous work (Nakach et al., 2014). The milled suspensions were prepared as follows:

- Suspension A made of API at concentration of $20 \%(\mathrm{w} / \mathrm{w})$ and SDS/PVP as wetting/dispersing agent at concentration of $1.2 \%$.

- Suspension C made of API at concentration of $20 \%(\mathrm{w} / \mathrm{w})$ and Solutol ${ }^{\circledR}$ as wetting/dispersing agent at concentration of $3 \%$.

$50 \mathrm{ml}$ aliquot of each suspension and $50 \mathrm{ml}$ of Cross-linked Polystyrene beads $(500 \mu \mathrm{m})$ were introduced in Nano-mill $01^{\circledR}$. The mill was operated during $150 \mathrm{~min}$ at $10.8 \mathrm{~m} / \mathrm{s}$. The mill temperature was maintained at $10^{\circ} \mathrm{C}$.

2.1.2.2. Perikinetic evaluation of milled suspension. There are two regions of coagulation: diffusion-controlled (fast coagulation) and reaction limited coagulation (slow coagulation) (Elimelech et al., 1995). It shall be assumed that every collision is effective in forming an aggregate (collision efficiency=1), so that the aggregation rate constant is the same as the collision rate constant (Pitt and Hounslow, 2015).

The aggregation process was considered to be represented by a second order kinetic (described by the Eq. (4)) as suggested by Schmoluchowski (for the fast coagulation rate) and by Fuchs for the slow coagulation rate (Fuchs, 1936; Schmoluchowski, 1917).

$\frac{d n_{t}}{d t}=k_{a} \times n_{t}^{2}=$ numberof collision where $\mathrm{n}_{\mathrm{t}}, \mathrm{t}$ and $\mathrm{k}_{\mathrm{a}}$ are the total number of particles, time and second order constant respectively. The Eq. (4) can be integrated with the initial condition $n_{t}=n_{0}\left(n_{0}\right.$ is the initial concentration of particles) to give Eq. (5).

$\frac{\mathbf{n}_{0}}{\mathbf{n}_{\mathbf{t}}}=1+\frac{\mathbf{t}}{\boldsymbol{\tau}} ;\left(\boldsymbol{\tau}=\frac{1}{\mathbf{K}_{\mathbf{a}} \mathbf{n}_{0}}\right)$

The characteristic time $\tau$ is often referred to as the half-life of aggregation. At this time the total number of particles in the dispersion has been reduced by a factor of 2 . In the region of reaction limited coagulation, the rate of coagulation is reduced due to the additional repulsive force from electrostatic or steric interaction. In this region, not every collision results in coagulation. Only a fraction $1 / \mathrm{W}$ of collisions is successful. $\mathrm{W}$ is commonly defined as the stability ratio, which is the ratio of the diffusion limited (fast) coagulation rate to the slow coagulation rate. When $\mathrm{W}=1$, the coagulation is in the diffusion-limited region.

$\mathbf{W}=\frac{\boldsymbol{\tau}(\text { fast })}{\boldsymbol{\tau}(\text { slow })}$

The characteristic time $\tau$ can be calculated from the slope of line represented by $n_{0} / n_{t}$ versus time $(t)$. The total number of particles at each time can be calculated from the weight-weight \% of suspension and the mass of a single particle that can be calculated from its volume and density according to the following equations,

$m_{\text {total }}=\left(\frac{\text { masse of sample }) \times(\% \text { ofsolid })}{100}\right)$

$m_{S P}=\rho \times V=\rho \times \frac{4}{3} \times \pi \times r^{3}$

$\boldsymbol{r}=\frac{\boldsymbol{d}}{2}$

$n_{t}=\frac{m_{\text {total }}}{m_{s p}}$

where, $m_{\text {total }}, m_{s p}, \rho, V, r$ and $d$ are the total mass of the particles, the mass of single particle, the density of particle, the volume of single particle, particle radius and particle diameter, respectively.

The aggregation rate measurement was carried out by following the particle size as a function of time using dynamic light scattering (DLS). Different solutions of varying ionic strength were prepared by diluting the appropriate $5.0 \mathrm{M}$ sodium chloride $(\mathrm{NaCl})$ standard solution with purified water. The milled suspension was diluted with purified water from $20 \% \mathrm{w} / \mathrm{w}$ to $0.1 \% \mathrm{w} / \mathrm{w} .10 \mu \mathrm{l}$ of this diluted suspension were added to $1 \mathrm{ml} \mathrm{NaCl}$ solution covering a wide range of concentration and the resulting suspension was gently mixed by hand in the DLS cuvette and then placed into the measuring cell of the DLS instrument.

2.1.2.3. Orthokinetic evaluation. In addition to the Brownian motion, particles movements and their collision rates can be modified by applying an orthokinetic force (shear-influenced aggregation induce by fluid transport). The rate of change in the total concentration of particles with time due to Orthokinetic aggregation is expressed as follow (Le Berre et al., 1998; Tolpekin et al., 2004).

$\frac{\mathrm{dn}_{\mathrm{t}}}{\mathrm{dt}}=-\frac{2 * \alpha * \dot{\gamma} * \mathrm{~d}^{3} * \mathrm{n}_{\mathrm{t}}^{2}}{3}$ 


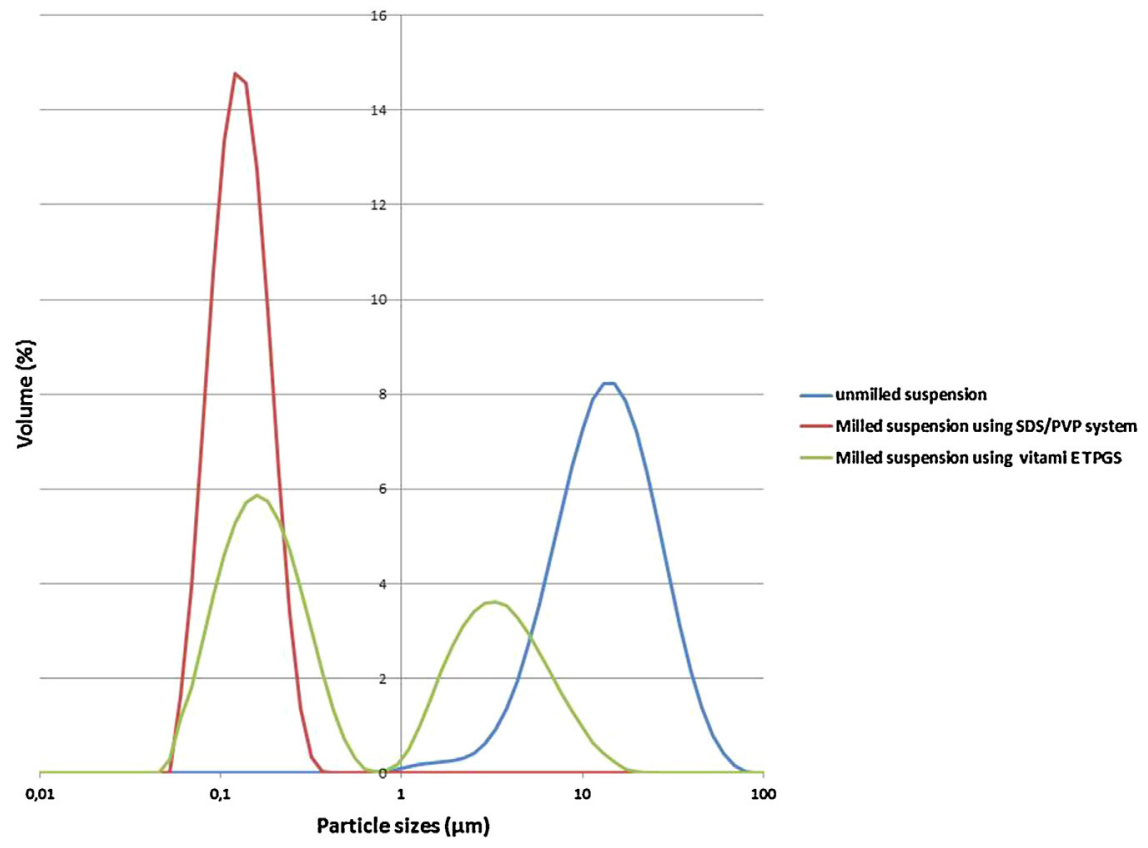

Fig. 1. Long milling duration trial $(n=1)$ : particle size distribution of SDS/PVP or vitamin E TPGS ${ }^{\circledR}$ at initial time and after $13 \mathrm{~h}$ of milling. The figure reflects that PVP/SDS system leads to a monomodal distribution. While, vitamin E TPGS ${ }^{\mathbb{R}}$ leads to bimodal distribution.

where, $\mathrm{n}_{\mathrm{t}}$ is the total concentration of particles in suspension at time t, $\alpha$ is the collision efficiency factor, $\dot{\gamma}$ is the mean shear rate and $\mathrm{d}$ is the particle diameter.

The ortho-kinetic evaluation was assessed on suspension of $20 \%$ API using a kinetic experiment by measuring the particle size (Laser diffraction). The evaluation was performed using annular mill without beads at $3880 \mathrm{rpm}(15 \mathrm{~m} / \mathrm{s})$, during $7 \mathrm{~h}$. The test was performed at native ionic strength (without salt addition) and at 0.17 molar of $\mathrm{Nacl}$ (corresponding to $0.24 \times$ CCC according to Sommer (2007)). The applied shear rate and shear strain were found equal to $26,000 \mathrm{~s}^{-1}$ and $6.5 \times 10^{8}$, respectively.

2.1.2.4. Measurement of desorption. The desorption of the wetting/ dispersing agent was carried out using a kinetic experiment by following the particle size as a function of time (up to $45 \mathrm{~min}$ ) using laser diffraction (Malvern Mastersizer 2000) in recirculation mode at $1800 \mathrm{rpm}$. The suspension was diluted by factor of 1000 .

2.1.2.5. Evaluation of $\mathrm{pH}$-induced aggregation. The aggregation rate measurement was carried out by monitoring the particle size as a function of time using dynamic light scattering. Solutions of different $\mathrm{pH}$ were prepared by diluting the appropriate $1.0 \mathrm{M}$ solution of hydrochloric acid $(\mathrm{HCl})$ and $1.0 \mathrm{M}$ solution of Sodium Hydroxide solution with purified water. The milled suspension was diluted with purified water from $20 \% \mathrm{w} / \mathrm{w}$ to $0.1 \% \mathrm{w} / \mathrm{w} .10 \mu \mathrm{l}$ of this diluted suspension were added to $1 \mathrm{ml}$ of acidic or basic solution covering a wide range of $\mathrm{pH}$ and the resulting suspension was gently mixed in the DLS cuvette and then placed into the measuring cell of the DLS instrument.

2.1.2.6. Evaluation of sensitivity of formulation to temperature. In order to evaluate the sensitivity of the formulation to Ostwald ripening and flocculation, solubility of API was measured as function of concentration of wetting/dispersing agent (SDS/PVP) as well as function of temperature in water. Then, the crystal growth was evaluated using temperature stress test.

2.1.2.6.1. Assessment of API solubility in water and in SDS/PVP solution. To assess API solubility a reverse phase HPLC-UV method was developed. The concentration of API was determined using a HPLC system composed of Varian Prostar ${ }^{\circledR}$ 230 pump (supplied by Varian France), injector Waters ${ }^{\circledR} 717$ plus (supplied by Waters ${ }^{\circledR}$ France) and UV absorbance detector (supplied by Thermo-Fisher ${ }^{\circledR}$ France) set at $232 \mathrm{~nm}$. The mobile phase was acetonitrile/Phosphate buffer pH $3.510 \mathrm{mM}(60 / 40, \mathrm{v} / \mathrm{v})$. A XTerra RP18 $50 \times 2.1 \mathrm{~mm}, 3.5 \mu \mathrm{m}$ column (supplied by Waters ${ }^{\circledR}$ France) was used with the flow rate set at $1.0 \mathrm{ml} / \mathrm{min}$ and the temperature set at $45^{\circ} \mathrm{C}$.

For the samples preparation $100 \mathrm{mg}$ of the API were introduced in vial containing the adequate solution. Then, the suspension was agitated using magnetic stirrer at fixed temperature during $4 \mathrm{~h}$ and let settle for $1 \mathrm{~h}$. The obtained supernatant was then filtered through $0.22 \mu \mathrm{m}$ PVDF $^{\circledR}$ filter (supplied by Millipore ${ }^{\circledR}$ ) and the filtrate was diluted using ethanol. The injected volume of the filtrate and the analysis time were fixed at $5 \mu \mathrm{l}$ and $2 \mathrm{~min}$ respectively. The chromatograms were analyzed using Empower ${ }^{\mathrm{TM}}$ chromatography software (supplied by Waters ${ }^{\circledR}$ France).

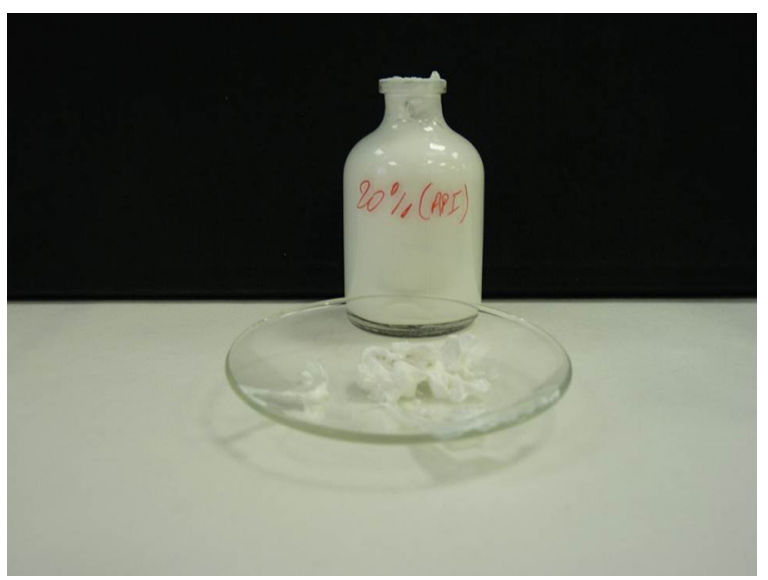

Fig. 2. Milled suspension of Vitamin E TPGS ${ }^{\mathbb{R}}$ showing that the suspension is gel like. 


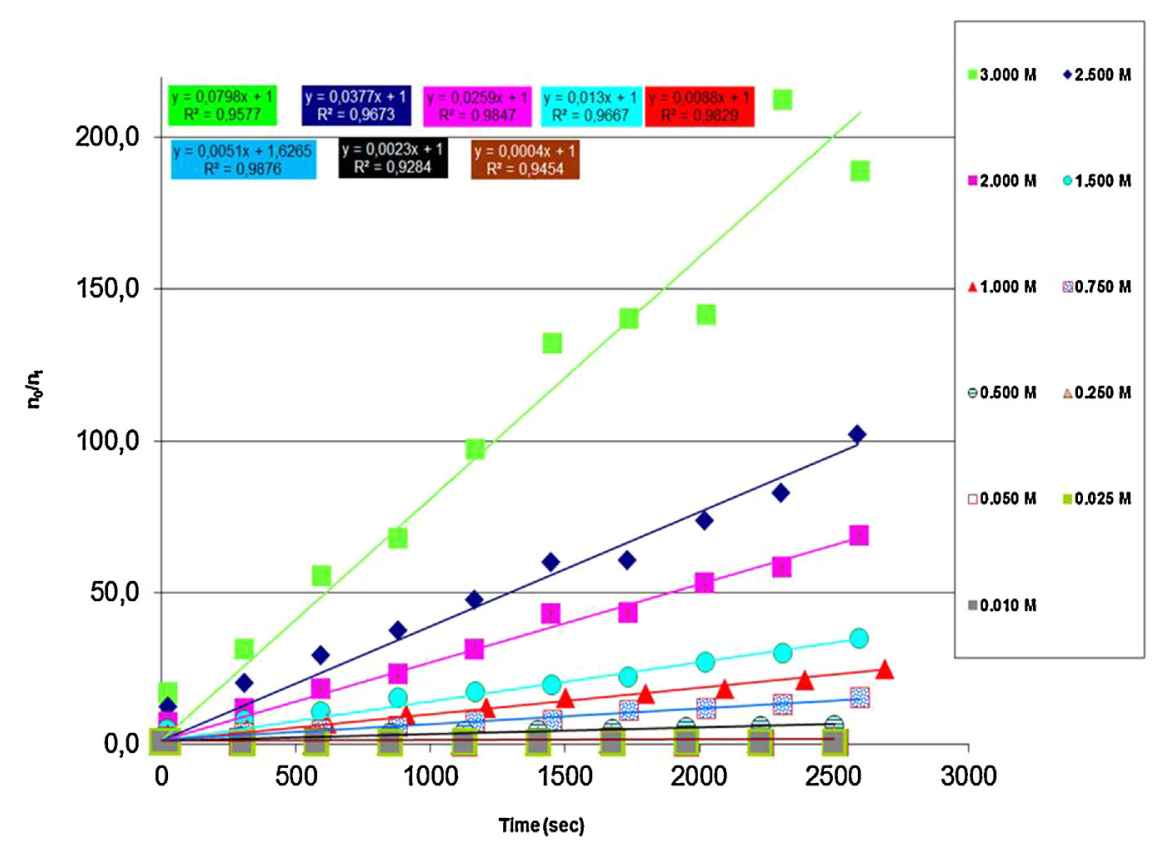

Fig. 3. $n_{0} / n_{t}$ (where $n_{0}$ is the initial number of particles, $n_{t}$ is the number of particles after time $(t)$ ) as function of time for different electrolyte concentrations ( $n=1$ ). The figure outlines that the higher is the concentration of electrolytes the higher is the aggregation rate. $\mathrm{ml}$.

The limit of quantification of method used was found at $0.1 \mu \mathrm{g} /$

Each measurement was done twice. A repeatability study was performed on 6 samples. A standard deviation of about $1.8 \%$ was determined.

2.1.2.6.2. Assessment of suspension stability as a function of temperature. The suspension stability was monitored by using kinetic experiment where particle size was measured (using laser diffraction) as function of storage time at different temperature: $20^{\circ}, 40^{\circ}, 50^{\circ}$ and $60^{\circ} \mathrm{C}$.

\subsubsection{Particle size measurement}

2.1.2.7.1. Laser diffraction. The particle size distribution of milled suspension was measured using Laser diffraction (Malvern Mastersizer 2000). This method is based on measurement of angle of light diffracted by particles, which depends on the particle radius using Fraunhofer diffraction theory. This method can measure particle sizes down to $1 \mu \mathrm{m}$. For smaller particles, forward light scattering is measured with application of Mie Theory of light scattering. By combining results obtained with light diffraction and forward light scattering, one can obtain particle size distributions in the range 0.02-10 $\mu \mathrm{m}$ (Swithenbank et al., 1976).

The symmetry of distribution can be evaluated using polydispersity index (PI) that is described by the following equation:

$\left.\mathrm{PI}=\ln \frac{\mathrm{d}_{10} * \mathrm{~d}_{90}}{\mathrm{~d}_{50}^{2}}\right)$

where, $\mathrm{d} 10, \mathrm{~d} 50, \mathrm{~d} 90$ are the characteristic diameters of particles distribution referring respectively to diameter of $10 \%, 50 \%$ and $90 \%$ of particles population

Three situations may be encountered. They are described below:

(i) $\mathrm{PI}=0$ for log-normal distribution

(ii) $\mathrm{PI}<0$ for dissymmetric distribution towards small diameters $\mathrm{d}_{50} / \mathrm{d}_{10}>\mathrm{d}_{90} / \mathrm{d}_{50}$

(iii) $\mathrm{PI}>0$ for dissymmetric distribution towards large diameters
The Mastersizer is equipped with lens having focal length of $550 \mathrm{~mm}$ and cell measurement having thickness of $2.4 \mathrm{~mm}$. The sample was diluted in $100 \mathrm{ml}$ of purified water and introduced in MS1 sampler. The suspension was stirred at 1500 r.p.m and recirculated through the measurement cell. The dilution factor was adjusted in order to ensure an obscuration in the range of 2.5-4.5. The measurements were carried out at room temperature. Each measurement was performed during $20 \mathrm{~s}$ and repeated 3 times. The refractive index of the API and dispersing were fixed at 1.61 and at 1.33 , respectively.

A repeatability study was performed on 10 samples. The standard deviation of about $1 \%$ was determined.

2.1.2.7.2. Dynamic light scattering. The dynamic light scattering (DLS) was used for the aggregation rate measurements as function of $\mathrm{pH}$ and ionic strength using Malvern Zetasizer instrument. The method referred to as photon correlation spectroscopy (PCS). The method is based in measuring the intensity fluctuation of scattered light as the particles undergo Brownian diffusion. From the intensity fluctuation one can calculate the diffusion coefficient D from which the particle diameter $\mathrm{d}$ is estimated using the Stoeckes-Einstein equation (see Eq. (12)) (Pecora, 1985) where, $\mathrm{D}$ is the diffusion coefficient, $\mathrm{k}_{\mathrm{B}}$ is Boltzmann constant, $\mathrm{T}$ is the absolute temperature, $\eta$ is the viscosity of the medium and $d_{h}$ is

Table 2

Rate of aggregation and stability ratio as function of sodium chloride concentration. The Table shows that higher is the sodium chloride, higher is the aggregation rate and lower is the stability ratio.

\begin{tabular}{llc}
\hline $\mathrm{NaCl}$ concentration $(\mathrm{M})$ & Rate of aggregation; $\tau\left(\mathrm{s}^{-1}\right)$ & Stability ratio; $\mathrm{W}$ \\
\hline 3.03 & $3.0010^{-11}$ & 1.00 \\
2.51 & $1.0010^{-11}$ & 3.00 \\
2.00 & $1.0010^{-11}$ & 3.00 \\
1.50 & $5.0010^{-12}$ & 6.00 \\
1.01 & $3.0010^{-12}$ & 10.00 \\
0.75 & $2.0010^{-12}$ & 15.00 \\
0.50 & $9.0010^{-13}$ & 33.00 \\
0.25 & $1.0010^{-13}$ & 300.00 \\
\hline
\end{tabular}




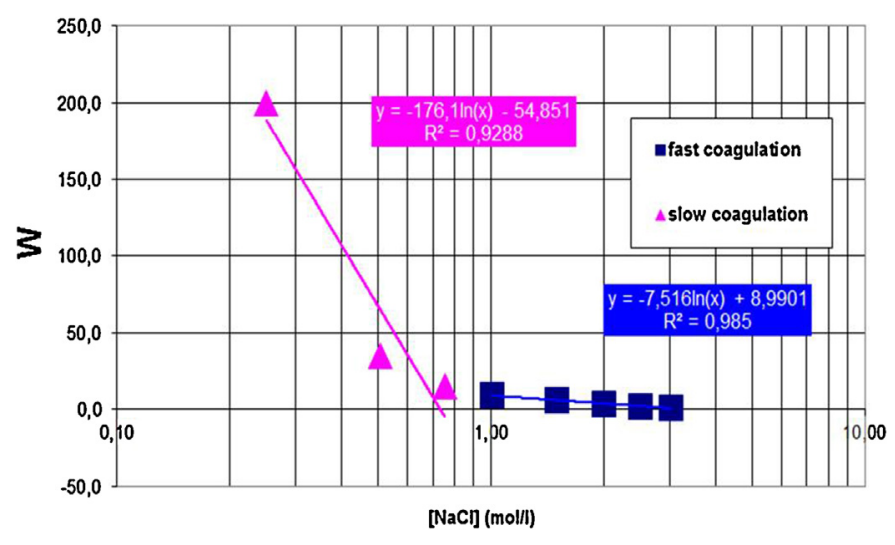

Fig. 4. Stability ratio $(W)$ as function of electrolyte concentration $(n=1)$. The figure gives a rough estimate of the $\mathrm{CCC}$ of $\mathrm{NaCl}(\sim 0.7$ molar) for the designed nanosuspension. the hydrodynamic diameter of the particles.

$D=\frac{k_{B} T}{3 \pi \eta d_{h}}$

The measurements were carried out using a scattering angle of $90^{\circ}$.

Each measurement was repeated 3 times. A repeatability study was performed and 10 samples. The standard deviation was determined as $0.8 \%$.

\section{Results and discussion}

\subsection{Long milling duration trial}

The results reveal that the SDS/PVP system leads to a suspension with particle size in the nanometric range (see Fig. 1) having mono-modal distribution and polydispersity index of 0.003 indicating that the particle size distribution is close to Lnnormal distribution. In contrast, the vitamin E TPGS ${ }^{\circledR}$ led to a
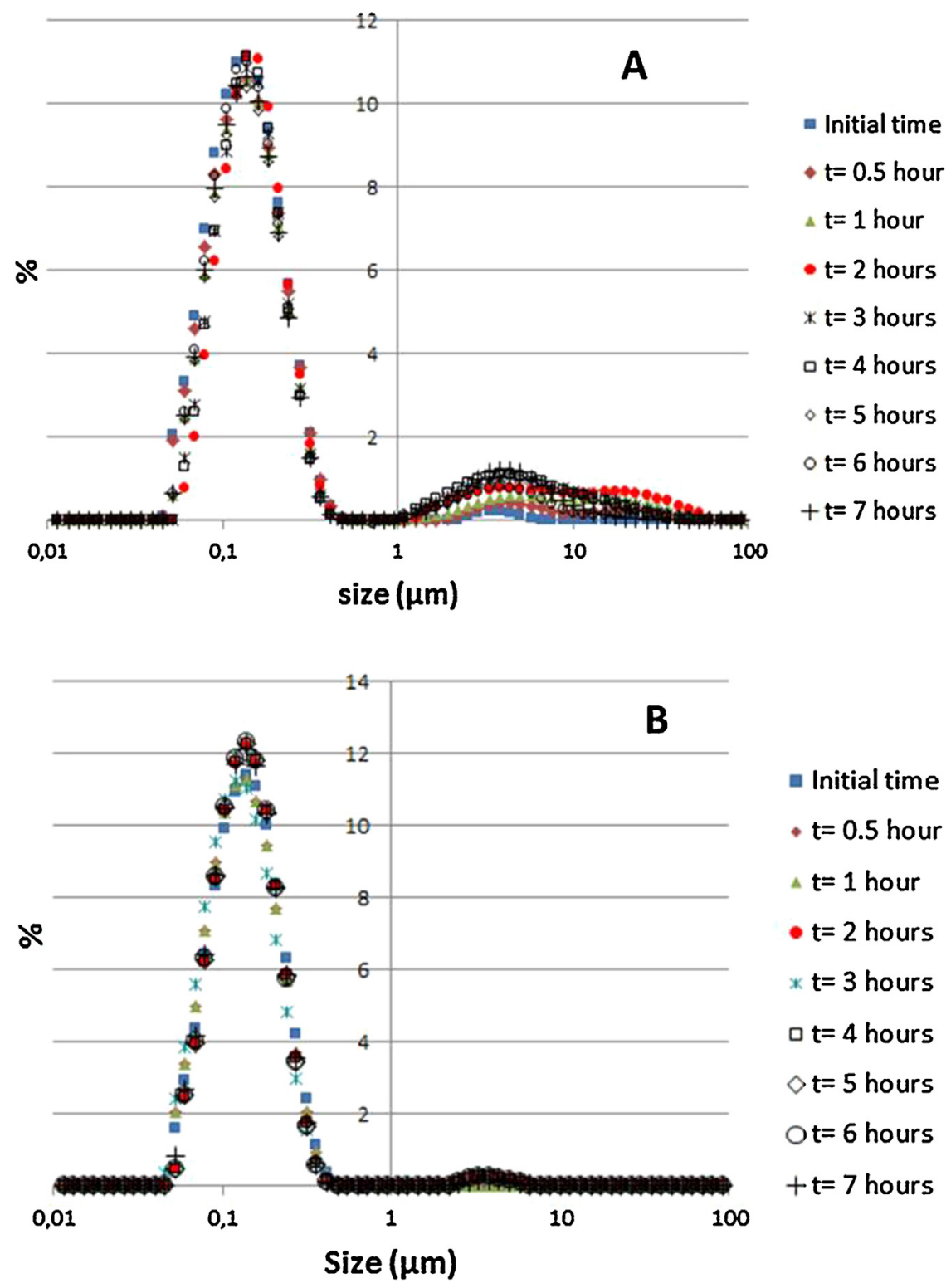

Fig. 5. Ortho-kinetic evaluation ( $\mathrm{n}=1)$ : monitoring of the particle size as function of time $(\mathrm{n}=1)$ at 2 ionic strengths (native without added salt and 0.17 molar of NaCl). The figure shows that without salt addition (A) the shear induced aggregation rate is much higher than when the salt is added at 0.17 molar (B). 
suspension with particle size in the micron range exhibiting bimodal distribution (see Fig. 1) with polydispersity index of 1.874 indicating that the particle size distribution is dissymmetric towards large diameters. Furthermore, as illustrated in Fig. 2, the milled suspension made from vitamin $\mathrm{E}^{\text {TPGS }}{ }^{\mathbb{R}}$ exhibited a gel aspect after milling. Whereas, the suspensions made of SDS/PVP remained fluid. It is noteworthy that during our previous work, after $1 \mathrm{~h}$ of milling, the suspension made of vitamin E TPGS ${ }^{\mathbb{R}}$ had a mono-modal distribution in nanometric range. We propose the following interpretations to explain the result obtained with vitamin E TPGS ${ }^{\circledR}$ :

- The aggregation can be due to the applied stress during a long period and absence of electrostatic stabilization (Anderson and Lekkerkerker, 2002). In fact in our previous work, we found that SDS/PVP system had a zeta potential of $-54 \mathrm{mV}$ and its stabilizing mechanism is electro-steric repulsion, while, vitamin E TPGS ${ }^{\circledR}$ has a zeta potential of $-22 \mathrm{mV}$ and its stabilizing mechanism is steric repulsion.

- Another mechanism that can explain the observed result is the gelation of polymer under shear flow (Omari et al., 2003). We assume that free and adsorbed vitamin E TPGS ${ }^{\circledR}$ on thenanoparticles bridge together under shear stress and form gel network that binds the nanoparticles together.

\subsection{Evaluation of perikinetic aggregation: measurement of critical coagulation concentration}

The milled suspension used for this evaluation had a particle size distribution similar to that shown in Fig. 1 (milled suspension using SDS/PVP system)

Fig. 3 shows the variation of $n_{0} / n_{t}$ as function of time. Noteworthy, $\mathrm{n}_{0} / \mathrm{n}_{\mathrm{t}}$ starts to increase with time when $\mathrm{NaCl}$ concentration was larger than $0.25 \mathrm{M}$. The plots gave straight lines indicating that the process of aggregation follows a second order kinetic. The characteristic times $\tau$ were calculated from the slope of the fitted lines.

The stability ratios were calculated according to Eq. (6) where the fast aggregation corresponds to ionic strength $3 \mathrm{M}$ in Fig. 3. Indeed, further increase in ionic strength does not increase the rate of aggregation. Consequently, this limit was considered as the fast aggregation rate ( $\tau$ (fast)).

The results for $\tau$ and $\mathrm{W}$ are summarized in Table 2 .

The stability ratio, $\mathrm{W}$, as function of electrolyte concentration is plotted in Fig. 4. One can estimate that at a critical electrolyte concentration $(\sim 0.7 \mathrm{M}$ of $\mathrm{NaCl})$, all the repulsive forces have been effectively screened and coagulation process was purely controlled by diffusion.

The value of measured CCC indicates a high colloidal stability of designed system. In fact, it is about five times higher than that observed in the literature for suspension colloidaly stable at high concentration (He et al., 2007; Serra et al., 2016).

\subsection{Evaluation of orthokinetic aggregation}

The results showed that, in the absence of added salt (see Fig. 5A), aggregation and increase of polydispersity index (dissymmetric distribution towards large diameters) (Fig. 6) are observed over time. In contrast, in the presence of $0.17 \mathrm{M}$ of $\mathrm{NaCl}$ (Fig.B) less aggregation and less increase of polydispersity index (Fig. 6) were observed over time. These results may seem counterintuitive. Indeed, under high shear rate, a high colloidal stability aws observed at ionic strength of $0.24 \times$ CCC than at very low ionic strength (without salt addition). This observation is in contradiction with results observed during perikinetic evaluation. We propose the following interpretations to explain the obtained results.

At low ionic strength, the PVP molecules are highly soluble in water. Under high shear rate, the polymers chains are may be extracted from nanoparticles. Hence, the steric repulsion and a major part of electrostatic repulsion are eliminated. Furthermore, the high shear rate can overcome the electrostatic barrier resulting in orthokinetic aggregation. In contrast, in the presence of $0.17 \mathrm{M}$ $\mathrm{NaCl}$, the low solubility of PVP molecules in the medium leads to a strong adsorption onto the particles. In this case, the shear induced aggregation is prevented. It is noteworthy that one can estimate which mechanism prevails by means of the Peclet number of the particles defined as the ratio of the time scale of convective transport due to shear over the time scale of diffusive transport (see Eq. (14)) (Ehrl et al., 2009). In our case the Peclet's number was found about 77 which is much higher than 1 outlining that the aggregation takes place in orthokinetic regime and the energy used to approach particles between them is likely much higher than DLVO potential barrier.

$\mathbf{P e}=\frac{6 \times \boldsymbol{\pi} \times \boldsymbol{\eta} \times \mathbf{r}^{3} \times \boldsymbol{\psi}}{\mathbf{K}_{\mathbf{B}} \times \mathbf{T}}$

where, $\eta$ is the dynamic viscosity, $\dot{\gamma}$ is the shear rate, $\mathrm{r}$ is the characteristic length-scale (particle radius), $K_{B}$ is the Boltzmann constant, and $\mathrm{T}$ is the absolute temperature.

\subsection{Desorption evaluation}

Fig. 7A reveals that the particle size distribution of suspension made of SDS/PVP system is unchanged over time indicating the high colloidal stability of the nano-suspension. In contrast, the results obtained with Solutol ${ }^{\mathbb{R}}$ system showed a notable change of particle size distribution as function of time (see Fig. 7B) indicating the aggregation of the nano-suspension. These results are in agreement with those observed in our previous work. In fact, the SDS/PVP system was found to exhibit high affinity adsorption isotherm which is known as irreversible process. In contrast, the Solutol ${ }^{\circledR}$ adsorption is weak and reversible.

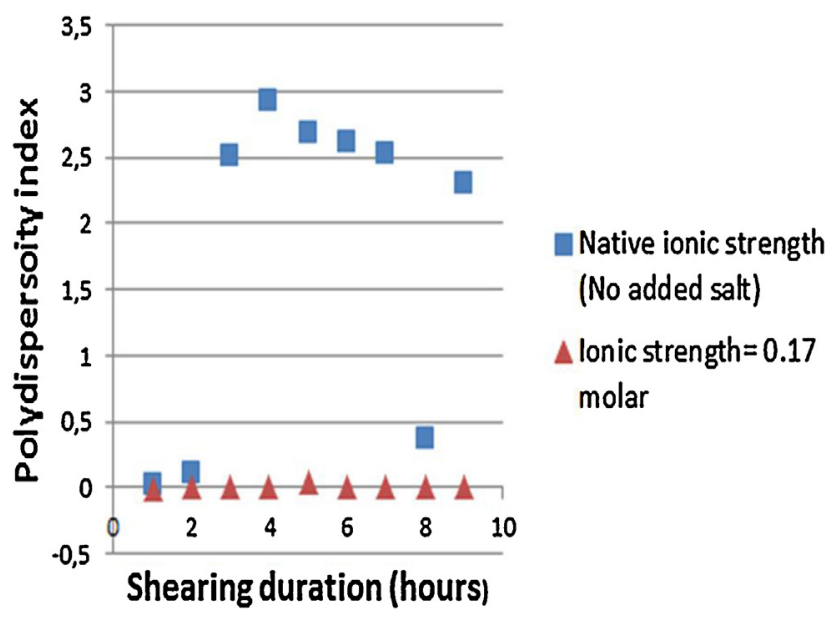

Fig. 6. Ortho-kinetic evaluation: polydispersity index as function of time $(n=1)$ at 2 ionic strengths (native without added salt and 0.17 molar of $\mathrm{NaCl}$ ). The figure shows that without salt addition the polydispersity index is much higher than when the salt is added at 0.17 molar. 


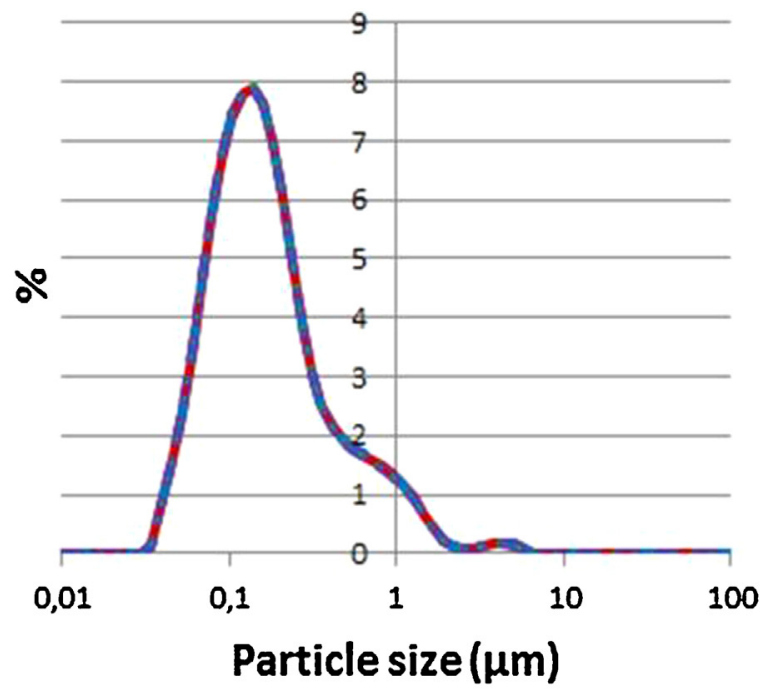

A

Initial time

- After $11 \mathrm{~min}$

After $33 \mathrm{~min}$

○o.After $43 \mathrm{~min}$

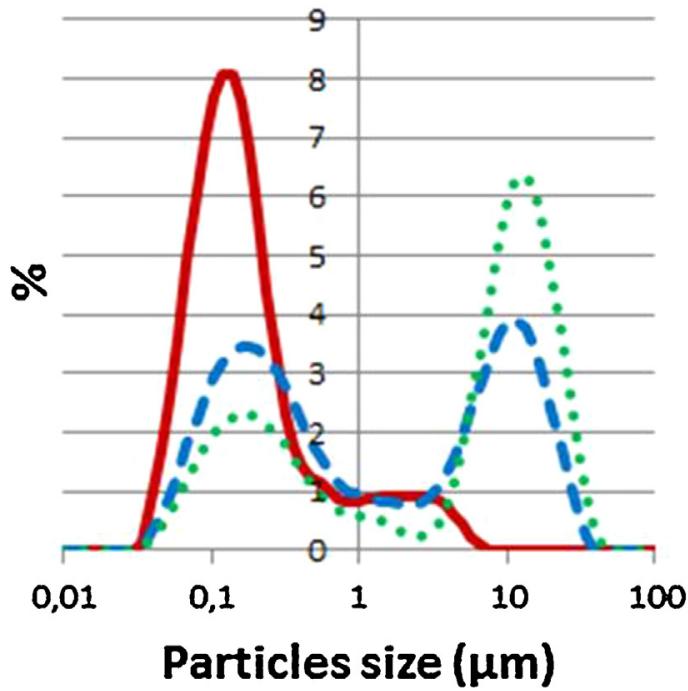

B

Initial time

- - After $11 \mathrm{~min}$

.....After $21 \mathrm{~min}$

Fig. 7. Assessment of desorption of the wetting/dispersing agent $(n=1)$ : monitoring of the particle size as function of time for SDS/PVP system (A) and for Solutol ${ }^{\mathbb{B}}$ (B). The figure emphasized that the SDS/PVP system exhibits irreversible adsorption as no aggregation was highlighted during dilution. In contrast, high aggregation was observed with Solutol ${ }^{\mathbb{R}}$

\subsection{Sensitivity to ostwald ripening and flocculation}

3.5.1. API solubility as function of wetting/dispersing agent (SDS/PVP) concentration in water

Fig. 8 represents the API solubility as function of PVP, SDS and SDS-PVP (at ratio of $40-60 \%(w / w)$ ) concentration. It has been observed that:

- The API solubility does not change with increase of PVP concentration,

- The API solubility increases with SDS concentration

- The API solubility increases sharply with SDS-PVP (at ratio of 40$60 \% \mathrm{w} / \mathrm{w}$ ) concentration.

The impact of SDS concentration on API solubility is straightforward. It means, above the critical micellar concentration (CMC), the formed micelles can solubilize ' $N$ ' number of API molecules per micelle. The dissolved amount of API by micelle is therefore proportional to formed micelles as described by the Eq. (15)

$\boldsymbol{S}=\boldsymbol{S}_{0}+\boldsymbol{N}_{A P I} \times M_{A P I}\left(\frac{C-C M C}{M_{S D S} \times N_{a g}}\right)$

where, $S, S_{0}, N_{A P I}, M_{A P I}, C, C M C, M_{S D S}$ and $N_{\text {ag }}$ are the API solubility in SDS/PVP solution, API solubility in water, number of API molecules per micelle, API molecular weight, SDS/PVP concentration, critical micellar concentration of SDS, SDS molecular weight and number of micelles aggregation, respectively.

As PVP alone does not solubilize the API, the increase of API solubility when PVP is added to SDS is difficult to understand. This phenomenon in fact can be explained by the subtle mechanism: According to Shirahama et al. (1974) and Cabane (1977), at critical aggregation concentration (well below the $\mathrm{CMC}$ ), polymer chains interact with surfactant to form small micelles of surfactant inside the polymer chain (see Fig. 9). Therefore, in presence of polymer much higher number of micelles are formed. The higher number of micelles explains the high solubility. 


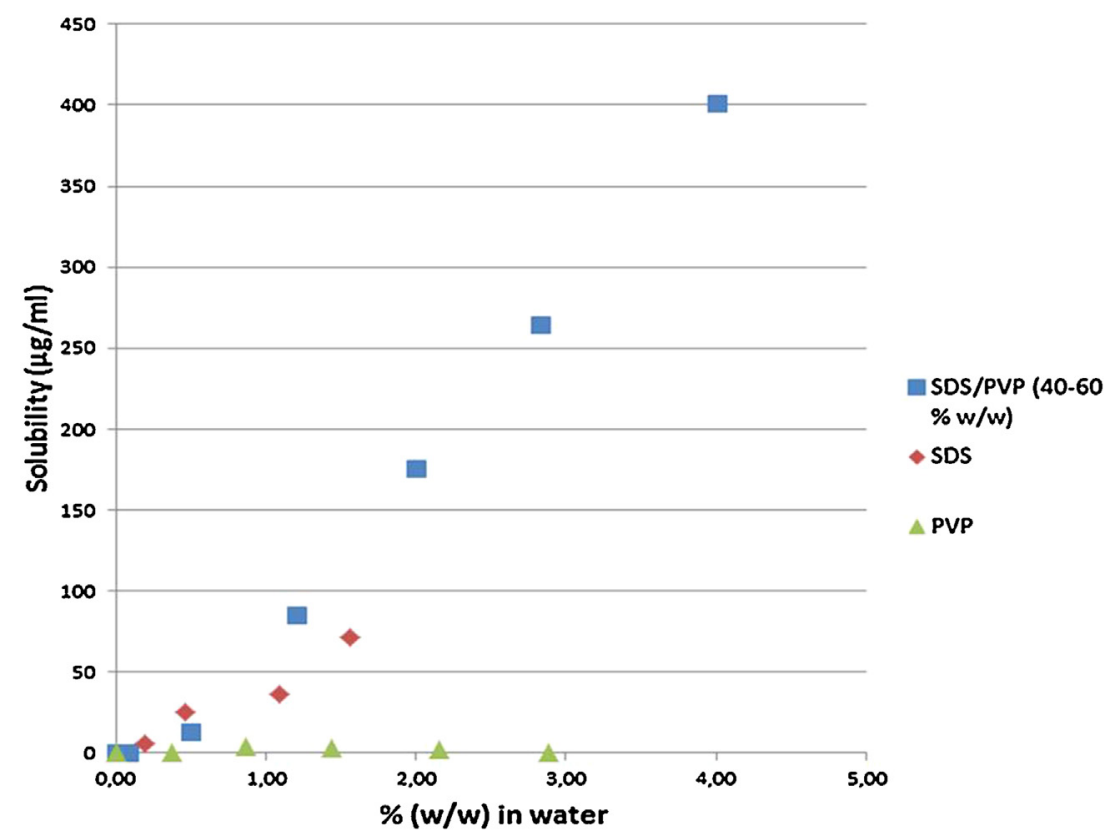

Fig. 8. API solubility as function of concentration in SDS/PVP solution (at ratio of $40-60 \% \mathrm{w} / \mathrm{w})$, SDS solution and PVP solution at $20{ }^{\circ} \mathrm{C}(\mathrm{n}=2)$. The figure highlights that the API solubility is much higher when the SDS/PVP system is used as medium than when SDS or PVP are used alone. This outlines that the API solubility is driven by the synergy of SDS and PVP molecules.

3.5.2. API solubility as function of temperature in (SDS/PVP) solution at concentration of $1.2 \%$

The obtained results show that the API solubility does not change with increase of temperature when water is used as vehicle. However, when solution containing $1.2 \%$ of SDS/PVP at ratio of 40 $60 \%(\mathrm{w} / \mathrm{w})$ is used, the API solubility decreases surprisingly with increase of temperature (see Fig. 10A). This result can be interpreted by the disaggregation effect of temperature (above room temperature) on SDS micelles. In fact, increase of temperature causes disruption of the structured water surrounding the hydrophobic groups which disfavors micellization (Sakhawat Shah and Ejaz-Ur-Rehman, 1987). Furthermore, this phenomenon can be heightened by solubilisation of PVP molecules at high temperature.

Both the observations indicate that the heat induced Ostwald ripening hypothesis can be ruled out. Indeed, the diffusion of dissolved API to solid particles cannot take place from the micellar system as it is attached to the solid particles.

\subsection{Temperature stress test}

During milling, the suspension undergoes wide amplitude of temperature. The impact of temperature on particle size of suspension $(20 \% \mathrm{w} / \mathrm{w}$ of API) was evaluated in the range of 20 $60^{\circ} \mathrm{C}$. The results show that at $20^{\circ} \mathrm{C}$, the dispersion remains stable for more than $600 \mathrm{~h}$, showing no increase in particle size with time. As the temperature increases to $40^{\circ}, 50^{\circ}$ and $60^{\circ} \mathrm{C}$, significant increase of particle size with time is observed (see Fig. 11A). Moreover, as can be seen in Fig. 11B, when the temperature increases, the polydispersity index increases over time indicating a dissymmetric distribution of particles towards large diameters.

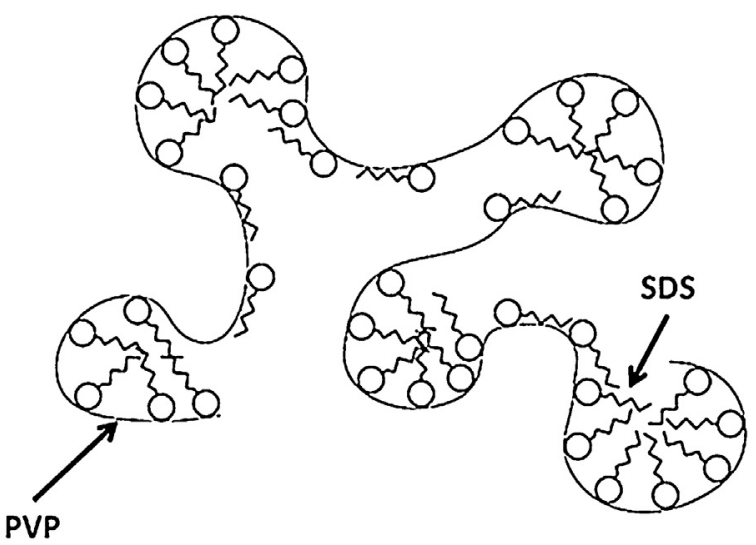

Fig. 9. PVP molecules and SDS micelles arrangement. The conformation reflects that The SDS micelles are trapped by the PVP chains which may provide a high electrosteric barrier.

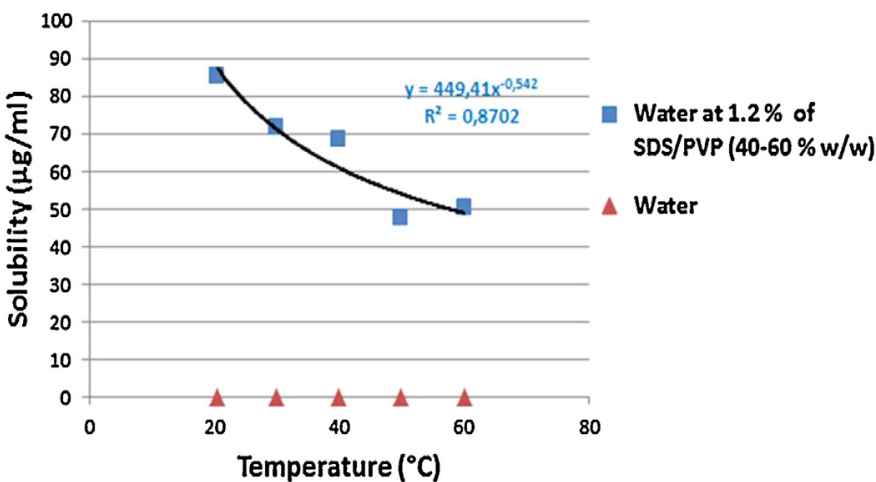

Fig. 10. API solubility in SDS/PVP (at ratio of $40-60 \% \mathrm{w} / \mathrm{w}$ ) solution at concentration of $1.2 \% \mathrm{w} / \mathrm{w}$ and in water at different temperatures $(n=2)$. The figure shows that the increase of temperature does not impact the API solubility when water is used as medium. In contrast, the API solubility decreases when the temperature is increased for SDS/PVP solution. 
Hypothetically, this increase could be due to either Ostwald ripening or flocculation. Ostwald ripening can be ruled out since a plot of crystal growth $\left(r^{3}(t)-r^{3}{ }_{(0)}\right)$ versus time did not give a linear relationship (see Fig. 12) (Lifshitz and Slyozov, 1961; Wagner, 1961). In addition, monitoring of particle size distribution showed that the appearance of coarse particles is not due to disappearance of fine particles (see Fig. 13). Thus, the increase in particle size with time must be due to flocculation. These results from either desorption of the dispersing agent (PVP molecules) which becomes more soluble at high temperature (Tadros, 2012) or degradation of SDS at high temperature. Indeed, prolonged heating of SDS at $40^{\circ} \mathrm{C}$ or greater causes decomposition of alkylsulfates into fatty alcohols and sodium sulfate (Anon., 1970; Specification, 2012).

\subsection{Sensitivity to $\mathrm{pH}$ variations}

The impact of $\mathrm{pH}$ on particle size of suspension (20\% of API) was evaluated in the range of 2.0-9.5 to mimic gastric $\mathrm{pH}(1.50-5.00)$, intestinal $\mathrm{pH}$ (7.40-7.80) or plasmatic $\mathrm{pH}$ (7.35-7.45). The results show (see Fig. 14) that particle size did not change over time when the $\mathrm{pH}$ was higher than 2 indicating high robustness of the designed formulation. At $\mathrm{pH} \mathrm{2,} \mathrm{a} \mathrm{strong} \mathrm{destabilization} \mathrm{of}$ suspension was observed. In fact, a spontaneous increase of particle size was observed soon after introduction of the sample within the acidic solution followed by a continuous linear increase of the particle size. This may be due to the contribution of two mechanisms:

(i) pKa of SDS is close to the second acidity of sulfuric acid (1.9). At $\mathrm{pH}$ above the pKa, the SDS loses its proton $\mathrm{H}^{+}$and become negatively charged to ensure electrostatic stabilization. At $\mathrm{pH}$ below pKa, the SDS recovers its proton and loses its negative charges and thus its function as electrostatic stabilizer.

(ii) Degradation of SDS. According to the handbook of pharmaceutical excipients SDS (Rowe et al., 2012) under extreme conditions i.e., $\mathrm{pH} 2.5$ or below, it undergoes hydrolysis to
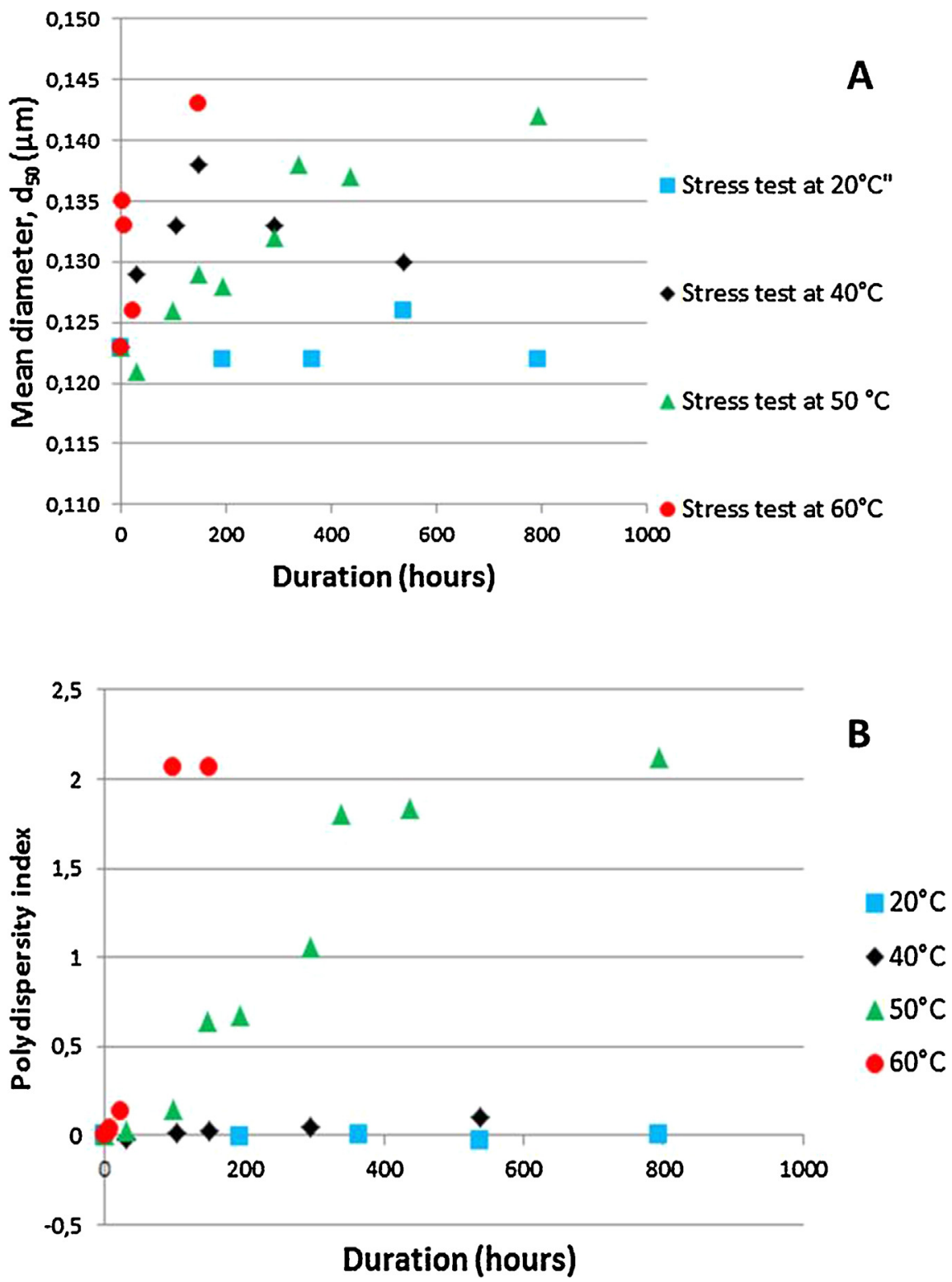

Fig. 11. Temperature stress test: Mean diameter (A) and Polydispersity index (B) as function of time at different temperatures ( $\mathrm{n}=1$ ). The figure does not reflect any change in particle size and polydispersity index at $20^{\circ} \mathrm{C}$. However, increase of particle size and polydispersity index is observed when the temperature is increased to $40^{\circ}, 50^{\circ}$ and $60^{\circ} \mathrm{C}$. 
A

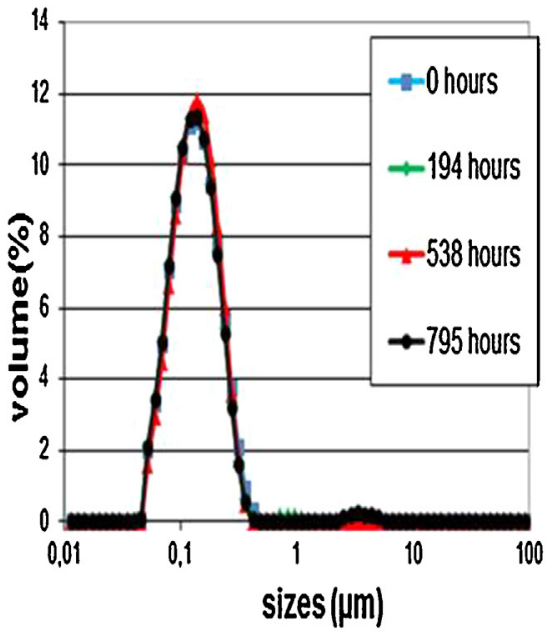

C

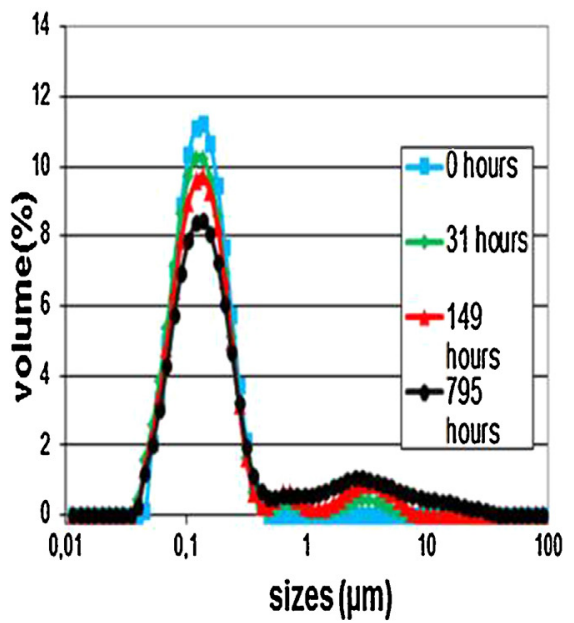

B

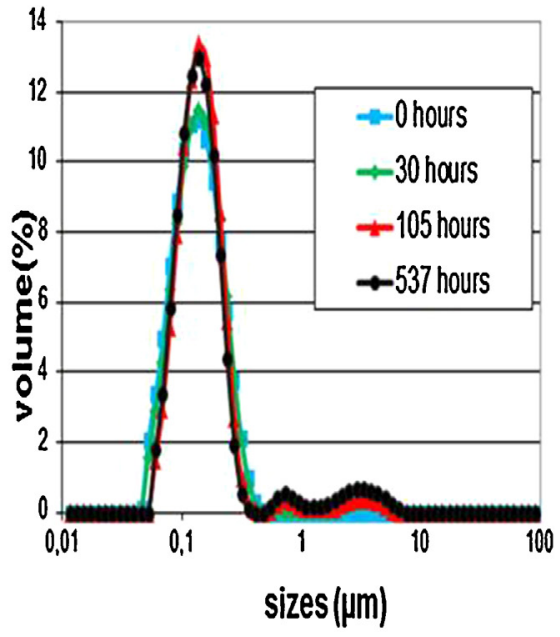

D

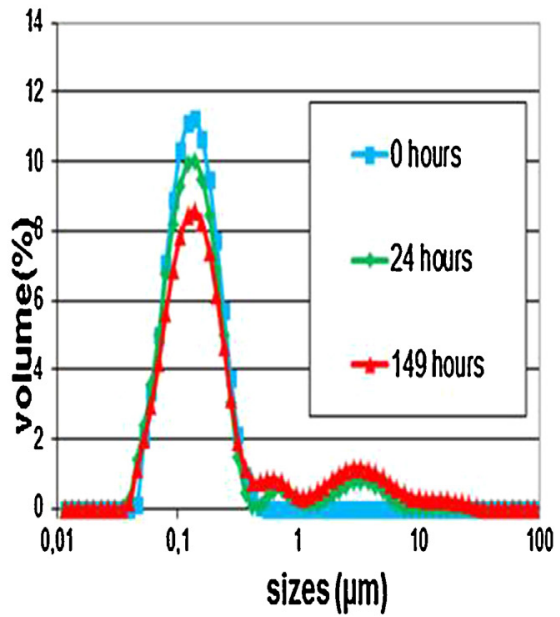

Fig. 12. Temperature stress test: monitoring of the particle size as function of time at $20^{\circ}$ (A), at $40^{\circ}(\mathrm{B})$, at $50^{\circ}$ (C) and at $60^{\circ} \mathrm{C}(\mathrm{D})$. The figure outlines that the appearance of coarse particles is not due to disappearance of small particles but to flocculation.

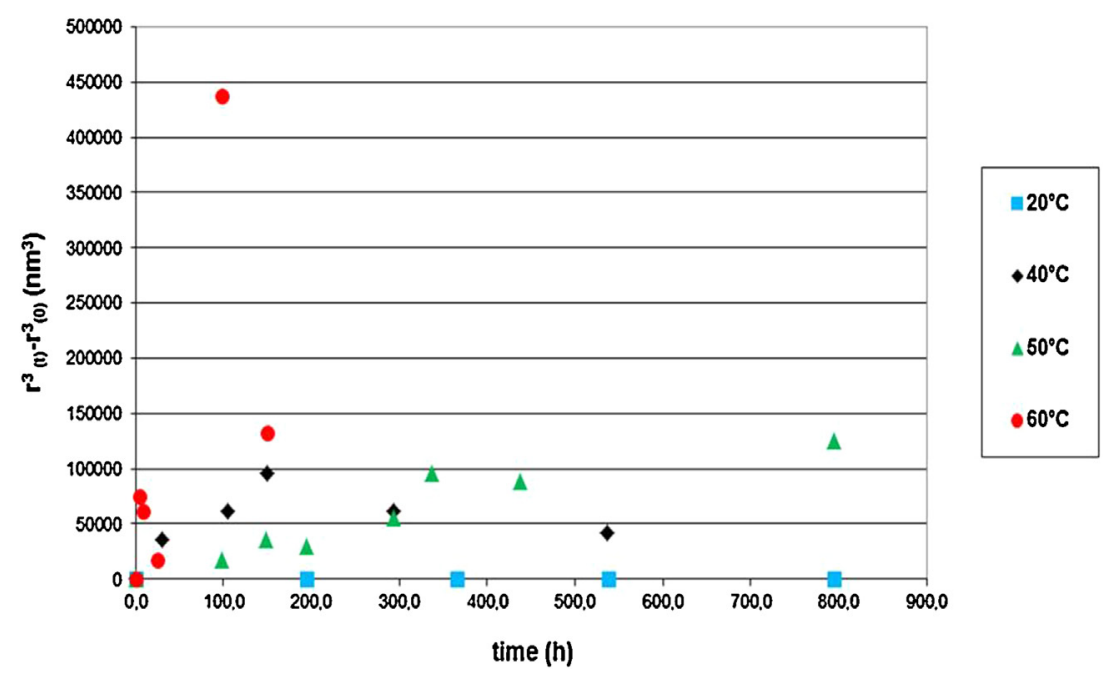

Fig. 13. Crystal growth as function of temperature $(n=1)$. The figure outlines that the ostwald ripening can be excluded as hypothesis as the graphs do not give a straight lines. 


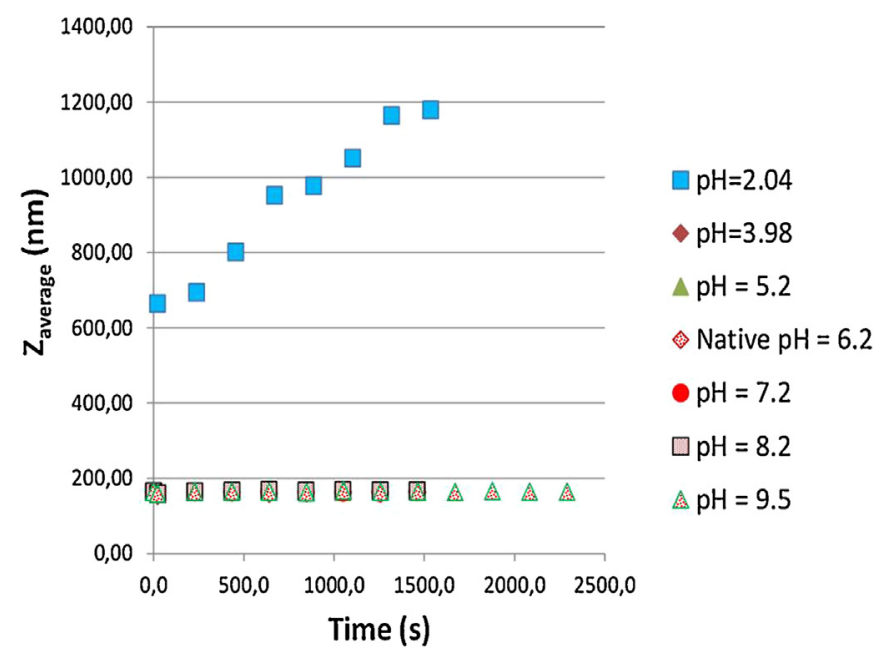

Fig. 14. $\mathrm{pH}$ stress test: Mean diameter as function of time at different $\mathrm{pH}$. The figure reflects that particle size was not changed over time when the $\mathrm{pH}$ was higher than 2 indicating highly colloidal stability of designed system.

lauryl alcohol and sodium bisulfate leading to a lack of electrostatic repulsion between particles.

\section{Conclusion}

Development of a robust formulation stable along the overall value chain (from manufacturing process until administration to patient) is vital. The experimental research methodology described in this paper represents an efficient approach for evaluating the formulation robustness of nano-crystalline suspension. The assessment of suspension destabilization under various conditions such as, ionic strength, shear rate, temperature, $\mathrm{pH}$ and dilution allowed identification of critical parameters whose levels must be tightly controlled to maintain product stability and thus in-vivo performances. A careful attention needs to be paid during downprocessing of suspension with regard to the applied shear rate and high temperature mainly during heat based process such as autoclaving where flocculation or aggregation may occur. It would be interesting to determine the limits of shear rate in which variations in the levels have minimal or no effect on product stability or in-vivo performances.

\section{Acknowledgments}

The authors gratefully acknowledge J.L. Laly (Global Head of Pharmaceutical Sciences Operations at Sanofi R\&D) for his support. The Authors acknowledge also Nait-Bouda Lahlou for his support for solubility measurements Bernard Cabane (ESPCI, France) and Harivardhan-Reddy Lakkiredy (Head of drug delivery at Pharmaceutical Sciences Operations (Sanofi R\&D-Paris) for their appreciated contributions to pre-review this paper.

\section{References}

Anderson, V.J., Lekkerkerker, H.N.W., 2002. Insights into phase transition kinetics from colloid science. Nature 416, 811-815.

Anon, 1970. Sodium dodecyl sulfate. Chemistry 72 .

Cabane, B., 1977. Structure of some polymer-detergent aggregates in water. J. Phys. Chem. 81, 1639.
Corti, M., Minero, C., Degiorgio, V., 1984. Cloud point transition in nonionic micellar solutions. J. Phys. Chem. 88, 309-317.

Ehrl, L., Soos, M., Morbidelli, M., Bäbler, M.U., 2009. Dependence of initial cluster aggregation kinetics on shear rate for particles of different sizes under turbulence. AIChE J. 55, 3076-3087.

Elimelech, M., Gregory, J., Jia, X., Williams, R.A., 1995. Particle Deposition and Aggregation. Published by B\&H.

Fuchs, N., 1936. Z. Phys 89, 736.

He, Y.T., Wan, J., Tokunaga, T., 2007. Kinetic stability of hematite nanoparticles: the effect of particle sizes. J. Nanopart. Res. 10, 321-332.

Hiemenz, P.C., Rajagopalan, R., 1997. Principles of Colloid and Surface Chemistry, 3rd ed. Marcel Dekker Inc., NewYork, pp. 255-265.

Holthoff, H., Egelhaaf, S.U., Borkovec, M., Schurtenberger, P., Sticher, H., 1996. Coagulation rate measurements of colloidal particles by simultaneous static and dynamic light scattering. Langmuir 12, 5541-5549.

Jenkins, P., Snowden, M., 1996. Depletion flocculation in colloidal dispersions. Adv. Colloid Interface Sci. 68, 57-96.

Kiratzis, N., Faers, M., Luckham, P.F., 1999. Depletion flocculation of particulate systems induced by hydroxyethylcellulose. Coll. Surf. A 151, 461-471.

Lauten, R.A., Kjoniksen, A.L., Nystrom, B., 2001. Colloid polymer interactions and aggregation in aqueous mixtures of polystyrene latex, sodium dodecyl sulfate, and a hydrophobically modified polymer: a dynamic light scattering study. Langmuir 17 (3), 924-930.

Le Berre, F., Chauveteau, G., Pefferkorn, E., 1998. Perikinetic and orthokinetic aggregation of hydrated colloids. J. Colloid Interface Sci. 199, 1-12.

Lifshitz, I., Slyozov, V., 1961. The kinetics of precipitation from supersaturated solid solutions. J. Phys. Chem. Solids 19, 35-50.

Nakach, M., Authelin, J.R., Tadros, T., Galet, L., Chamayou, A., 2014. Engineering of nano-crystalline drug suspension: employing a physico-chemistry based stabilizer selection methodology or approach. Int. J. Pharm. 476, 277-288.

Omari, A., Chauveteau, G., Tabary, R., 2003. Gelation of polymer solutions under shear flow. Coll. Surf. A 225, 37-48.

Ostwald, W., 1901. Uber die vemeintliche Isomerie des roten und gelben Quecksilberoxyds und die Oberflachen-spannung Fester Korper. Z. Phys.Chem. 34, 495-512.

Patel, R.M., 2010. Parenteral suspension: an over view. Int. J. Curr. Pharm. Res. 2 4-13.

Pecora, R., 1985. Dynamic Light Scattering: Applications of Photon Correlation Spectroscopy. Springer.

Peltonen, L., Hirvonen, J., 2010. Pharmaceutical nanocrystals by nanomilling: critical process parameters, particle fracturing and stabilization methods. J. Pharm. Pharmacol. 62, 1569-1579.

Pitt, K., Hounslow, M.J., 2015. Aggregation of growing crystals in suspension: iI: Poiseuille flow crystalliser. Chem. Eng. Sci. 122, 384-394.

Potanin, A.A., 1991. On the mechanism of aggregation in the shear flow of suspensions. J. Colloid Interface Sci. 145, 140-157.

Rowe, R.C., Sheskey, P.J., Cook, W.G., Fenton, M.E., 2012. Handbook of Pharmaceutical Excipients, seventh edition .

Sakhawat Shah, S., Ejaz-Ur-Rehman, 1987. Effect of temperature and aprotic solvents on the CMC of sodium deodecyl sulphate. Book: Interaction of Water in Ionic and Nanionic Hydrates, , pp. 252-255.

Sato, T., Ruch, R., 1980. Stabilization of Colloidal Dispersions by Polymer Adsorption. Marcel Dekker, Inc., New York.

Schmoluchowski, M., 1917. Z. Phys. Chem. 92, 129-168.

Serra, J., Puig, J., Martín, A., Galisteo, F., Gálvez, M., Hidalgo-Alvarez, R., 2016. On the adsorption of IgG onto polystyrene particles: electrophoretic mobility and critical coagulation concentration. Colloid. Polym. Sci. 270, 574-583.

Shegokar, R., Müller, R.H., 2010. Nanocrystals: industrially feasible multifunctional formulation technology for poorly soluble actives. Int. J. Pharm. 399, 129-139. Shirahama, K., Tsuji, K., T.T, 1974. J. Biochem. 75.

Sommer, M.M., 2007. Mechanical production of nanoparticles in stirred media mills. Thesis. Fakultat der Universitat Erlangen-Nurnberg.

Specification, P., 2012. Sodium Dodecyl Sulfate vol. 2012., pp.1-2. nationalbiochem. com.

Spicer, P.T., Keller, W., Partsinis, S.E., 1996. The effect of impeller type on floc size and structure during shear-Induced flocculation. J. Colloid Interface Sci. 184, 112122.

Swithenbank, J., Beer, J., Taylor, D., Abbot, D., McCreath, G., 1976. A laser diagnostic technique for the measurement of droplet and particle size distribution. AIAA, Aerospace Sciences Meeting.

Tadros, T.F., 2012. Dispersion of Powders in Liquids and Stabilization of Suspensions. Book.

Tolpekin, V.A., Duits, M.H.G., van den Ende, D., Mellema, J., 2004. Aggregation and breakupof colloidal particle aggregates in shear flow studied with video microscopy. Langmuir 20, 2614-2627.

Wagner, C., 1961. Theorie der Alterung von Niederschla gen durch Umlo sen. Z. Elektrochem. 65, 581-591.

Yu, Y., von Gottberg, F., 2002. Coagulation kinetics of surface modified pigment particles. NIP \& Digital Fabrication Conference. Society for Imaging Science and Technology 383-387. 